\title{
Return of chloroquine-sensitive Plasmodium falciparum parasites and emergence of chloroquine-resistant Plasmodium vivax in Ethiopia
}

Seleshi Kebede Mekonnen ${ }^{1,2,3,7^{*}}$, Abraham Aseffa ${ }^{2}$, Nega Berhe ${ }^{1}$, Tilahun Teklehaymanot ${ }^{1}$, Ronald M Clouse ${ }^{5}$, Tamirat Gebru ${ }^{3,4}$, Girmay Medhin ${ }^{1}$ and Thirumalaisamy P Velavan ${ }^{3,6}$

\begin{abstract}
Background: Increased resistance by Plasmodium falciparum parasites led to the withdrawal of the antimalarial drugs chloroquine and sulphadoxine-pyrimethamine in Ethiopia. Since 2004 artemether-lumefantrine has served to treat uncomplicated $P$. falciparum malaria. However, increasing reports on delayed parasite clearance to artemisinin opens up a new challenge in anti-malarial therapy. With the complete withdrawal of CQ for the treatment of Plasmodium falciparum malaria, this study assessed the evolution of CQ resistance by investigating the prevalence of mutant alleles in the pfmdr1 and pfcrt genes in P. falciparum and pvmdr1 gene in Plasmodium vivax in Southern and Eastern Ethiopia.
\end{abstract}

Methods: Of the 1,416 febrile patients attending primary health facilities in Southern Ethiopia, 329 febrile patients positive for $P$. falciparum or $P$. vivax were recruited. Similarly of the 1,304 febrile patients from Eastern Ethiopia, 81 febrile patients positive for $P$. falciparum or $P$. vivax were included in the study. Of the 410 finger prick blood samples collected from malaria patients, we used direct sequencing to investigate the prevalence of mutations in pfcrt and pfmdr1. This included determining the gene copy number in pfmdr 1 in 195 P. falciparum clinical isolates, and mutations in the pvmdr 1 locus in 215 P. vivax clinical isolates.

Results: The pfcrt K76 CQ-sensitive allele was observed in $84.1 \%$ of the investigated P.falciparum clinical isolates. The pfcrt double mutations (K76T and C72S) were observed less than 3\%. The pfcrt SVMNT haplotype was also found to be present in clinical isolates from Ethiopia. The pfcrt CVMNK-sensitive haplotypes were frequently observed (95.9\%). The pfmdr 1 mutation N86Y was observed only in $14.9 \%$ compared to $85.1 \%$ of the clinical isolates that carried sensitive alleles. Also, the sensitive pfmdr 1 Y184 allele was more common, in $94.9 \%$ of clinical isolates. None of the investigated P. falciparum clinical isolates carried S1034C, N1042D and D1246Y pfmdr1 polymorphisms. All investigated P. falciparum clinical isolates from Southern and Eastern Ethiopia carried only a single copy of the mutant pfmdr1 gene.

Conclusion: The study reports for the first time the return of chloroquine sensitive P. falciparum in Ethiopia. These findings support the rationale for the use of CQ-based combination drugs as a possible future alternative.

Keywords: Malaria, Plasmodium falciparum, Plasmodium vivax, Ethiopia, pfcrt, pfmdr1, pvmdr1, pfmdr1 gene copy number

\footnotetext{
* Correspondence: se.kebede@gmail.com

'Aklilu Lemma Institute of Pathobiology, Addis Ababa University, Addis

Ababa, Ethiopia

${ }^{2}$ Armauer Hansen Research Institute, Addis Ababa, Ethiopia

Full list of author information is available at the end of the article
}

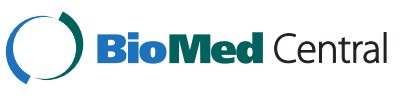

(c) 2014 Mekonnen et al.; licensee BioMed Central Ltd. This is an Open Access article distributed under the terms of the Creative Commons Attribution License (http://creativecommons.org/licenses/by/4.0), which permits unrestricted use, distribution, and reproduction in any medium, provided the original work is properly credited. The Creative Commons Public Domain Dedication waiver (http://creativecommons.org/publicdomain/zero/1.0/) applies to the data made available in this article, unless otherwise stated. 


\section{Background}

Malaria remains one of the major health problems in sub-Saharan Africa [1,2]. Though there are encouraging reports that malaria morbidity and mortality are declining [3], it is still an overwhelming public health problem, with an estimated 207 million cases and 627,000 deaths every year worldwide. Of all malaria deaths, $90 \%$ occur in sub-Saharan Africa, and $77 \%$ in children under five years of age [4]. One of the main obstacles to malaria control is the ability of the parasites to develop resistance to the administered anti-malarial drugs. Chloroquine $(\mathrm{CQ})$ was the first antimalarial to be widely used in endemic areas, but CQ resistance was documented in Thailand in the late 1950's, spread to African in 1974 [5], and subsequently came to East Africa in the early 1980's [6]. Since 2009, there are increasing concerns and reports of delayed parasite clearance to administered artemisinin, especially in parts of Southeast Asia [7].

In Ethiopia, CQ treatment failure for Plasmodium falciparum and Plasmodium vivax was documented in 1996 [8]. Therefore, in 1998 sulphadoxine-pyrimethamine (SP) replaced the CQ triple-dose ( $25 \mathrm{mg}$ base $/ \mathrm{kg}$ ) regimen as the first-line drug for the treatment of uncomplicated $P$. falciparum and mixed infection of $P$. falciparum and $P$. vivax malaria. However, in a short time span $P$. falciparum also developed resistance to SP, leading to therapeutic failure of SP [9-12]. Artemether-lumefantrine (AL) (Coartem ${ }^{\circ}$ ) replaced SP in 2004 as a first-line drug to treat uncomplicated $P$. falciparum and mixed infection of $P$. falciparum and P.vivax malaria in Ethiopia [13]. However CQ still remains the first-line drug to treat $P$. vivax malaria in Ethiopia and sub-Saharan Africa. Although significant progress has been made to understand the resistance mechanisms to administered anti-malarial drugs, the genetic basis of drug resistance is vital to implement strategies for efficient malaria control.

Point mutations in the genes " $P$. falciparum multidrug resistance 1" (pfmdr1), located in chromosome 5 [14-17], " $P$. falciparum chloroquine resistance transporter" (pfcrt), on chromosome 7 [18-20], and "P. vivax multi-drug resistance 1" (pvmdr1) on chromosome 10 [21-23] are the most investigated genes for anti-malarial drug resistance. Pfmdr1 encodes a trans-membrane transporter, and point mutations in this gene modulate the level of CQ resistance [24,25]. Other mutations are also associated with anti-malarial drug resistance and delayed parasite clearance $[15,17,26,27]$ : in the codons 86 (Asn86Tyr), 184 (Tyr184Phe), 1034 (Ser1034Cys), 1042 (Asn1042Asp), 1246 (Asp1246Tyr) in pfmdr1; codons 72 (Cys72Ser), 74 (Met74Ile), 75 (Asn75Glu) and 76 (Lys76Thr) in pfcrt; and codons 976 (Tyr976Phe) and 1076 (Phe1076Leu) in pvmdr1. Additionally, several other studies have also reported that $p f c r t$ haplotypes are associated with anti-malarial drug resistance $[19,25,28]$.
Gene copy number variations (CNV) in the $P$. falciparum genome have been shown to influence parasite phenotypes, and increased gene copy numbers are associated with reduced susceptibility to anti-malarial drugs.

Mutations in the pfmdr1 locus are associated with antimalarial resistance to chloroquine, mefloquine, quinine or artemisinin derivatives, whereas pfcrt mutations are associated with chloroquine, amodiaquine, mefloquine and artemisinin combination therapy [18]. Increased pfmdr1 gene copy numbers are associated with reduced susceptibility of P. falciparum to anti-malarial drugs, especially with artemether-lumefantrine and artesunate-mefloquine [29]. In many countries that are prone to malaria endemics, $P$. vivax malaria is treated with $\mathrm{CQ}$, as the drug is well tolerated, affordable, has a longer half-life, and protects from early relapses [30-32]. A decline in CQ efficacy for $P$. vivax malaria was reported in Papua New Guinea in 1989 [33] and in northwestern Sumatra, Indonesia in 1995 [34]. CQ resistance in $P$. vivax in Ethiopia was reported in 2008, when four patients out of $83(4.8 \%)$ had recurrent parasitaemia on Day 28 [35].

Several studies at regular intervals are required to evaluate drug resistance based on the genetic diversity of circulating $P$. falciparum strains and their molecular markers for P. falciparum resistance to CQ and AL. Such studies will lay a basis to re-evaluate existing strategies in malaria control [36]. In the present study, the prevalence of mutations in pfcrt and pfmdr1, the gene copy number of $p f m d r 1$ in P. falciparum, and point mutations in pvmdr1 in $P$. vivax were investigated in clinical isolates from Southern and Eastern Ethiopia.

\section{Methods}

Study sites

A health institution-based study targeting febrile patients attending primary health facilities was conducted in Southern and Eastern Ethiopia. Samples from Southern Ethiopia were collected between the months of August and December, 2011, at three health centres: Omo Nada, Bala Wajo, and Arba Minch. In Eastern Ethiopia samples were collected in the Harar health centre between the months of October and December 2009. Malaria transmission in these study sites is seasonal, with higher transmission following the rainy seasons (between September and December, and between April and May).

\section{Study samples}

Study participants were recruited from the routine health delivery system. Self-presenting febrile patients attending health centers in Omo Nada $(n=713)$, Bala Wajo $(\mathrm{n}=312)$, and Arba Minch $(\mathrm{n}=391)$, and whose age was at least six months between August and December 2011, were eligible for the current study. Additionally selfpresenting febrile patients attending Harar health centre 
$(n=1,304)$ in eastern Ethiopia were also eligible for the study. An axillary temperature was measured to check for a fever. Patients with an axillary temperature of $\geq 37^{\circ} \mathrm{C}$ were considered febrile. Any patient reported as being infected either with $P$. falciparum or $P$. vivax or with a mixed infection using the existing health care delivery system within the target health centres were approached for consent immediately after receiving their laboratory result. For those who consented to be part of the study, approximately $5-10 \mu \mathrm{L}$ of a finger-prick blood sample was collected. No additional clinical assessment was carried out at the time of recruitment. A total of 410 Southern and Eastern Ethiopian finger-prick blood samples collected on Whatman $3 \mathrm{~mm}$ filter paper tested positive by microscopy for either $P$. falciparum or vivax. Of these, 195 tested positive for P. falciparum (170 from Southern Ethiopia and 25 from Eastern Ethiopia), and 215 for P. vivax (159 P. vivax from Southern Ethiopia and 56 from Eastern Ethiopia). The blood spots were air-dried and stored in a separate, clean, sealed plastic bag at room temperature for further molecular analysis.

\section{Blood film management}

After fixing the thin film in methanol, both smears were stained with 3\% Giemsa for $30 \mathrm{~min}$ and examined under oil immersion for malaria parasites. Thick films were used for parasite detection, and thin film for species identification. At least 100 fields examined under an oil-immersion lens were examined before ruling out infection.

\section{Detection of pfmdr1, pfcrt and pvmdr1 polymorphisms}

DNA was isolated using the Qiagen DNA Mini Kit for blood and tissue (QIAGEN, Germany), following the manufacturer's instructions, and it was then stored at $-20^{\circ} \mathrm{C}$ until use. Nested PCR was carried out as previously described elsewhere [37]. DNA samples were amplified by species-specific primer pairs (Table 1). For $p f c r t$, pfmdr 1 and pvmdr1 both the primary and nested amplifications were carried out in a $20 \mu \mathrm{L}$ reaction volume containing $1 \mathrm{X}$ buffer, $2.5 \mathrm{mM} \mathrm{MgCl}_{2}, 200 \mu \mathrm{M}$ dNTPs, 200nM primers, $1 \mathrm{U}$ Taq DNA-Polymerase, and $10 \mathrm{ng}$ of DNA template on a PTC-200 Thermal cycler (MJ Research, USA). Each genus-specific amplification for Plasmodium was followed by a species-specific PCR. For amplifications, the study followed standard nested PCR procedure (Table 1). The PCR product of the first reaction was used as the template for the second in all nested PCRs. Amplicons that resulted from the nested PCRs were separated by electrophoresis on a $1.2 \%$ agarose gel, run with a 100 bp DNA ladder (Invitrogen, Karlsruhe, Germany). The presence of different Plasmodium species was re-confirmed by checking amplicon size. To identify relevant Single Nucleotide Polymorphisms (SNPs) in pfmdr1, pfcrt and pvmdr1, PCR products were cleaned using Exo-SAP-IT (USB, Affymetrix, USA), and $1 \mu \mathrm{L}$ of the purified product was used as a template for direct sequencing using the Big Dye terminator v. 2.0 cycle sequencing kit (Applied Biosystems, USA) on an ABI 3130XL DNA sequencer, according to the manufacturer's instructions [38]. All investigated

Table 1 Primer pairs used to amplify and sequence pfcrt, pfmdr1 and pvmdr1

\begin{tabular}{|c|c|c|c|}
\hline Gene fragment & Primer Name & Primer sequence & PCR cycling conditions \\
\hline Pfcrt SNPs at & OF P1 & 5'CCGTTAATAATAAATACACGCG & 35 cycles of $94^{\circ} \mathrm{C}$ for $30 \mathrm{~s} ; 56^{\circ} \mathrm{C}$ \\
\hline \multirow[t]{3}{*}{ Codon $72 \& 76$} & OR P2 & 5'CGGATGTTACAAAACTATAGTCC & for $30 \mathrm{~s}$; and $62^{\circ} \mathrm{C}$ for $1 \mathrm{~min}$; \\
\hline & NF P3 & 5'-AGGTTCTTGTCTTGGTAAATTTGC & 30 cycles of $94^{\circ} \mathrm{C}$ for $30 \mathrm{~s} ; 56^{\circ} \mathrm{C}$ \\
\hline & NR P4 & 5'-CAAAACTATAGTTACCAATITTG & for $30 \mathrm{~s}$; and $65^{\circ} \mathrm{C}$ for $1 \mathrm{~min}$; \\
\hline Pfmdr1 SNPs at & OF P5 & 5'-AGGTTGAAAAAGAGTTGAAC & 30 cycles of $94^{\circ} \mathrm{C}$ for $30 \mathrm{~s} ; 55^{\circ} \mathrm{C}$ \\
\hline \multirow[t]{3}{*}{ Codon 86\&184 } & OR P6 & 5'-ATGACACCACAAACATAAAT & for $30 \mathrm{~s}$; and $65^{\circ} \mathrm{C}$ for $1 \mathrm{~min}$; \\
\hline & NF P7 & 5'-ACAAAAAGAGTACCGCTGAAT & 30 cycles of $94^{\circ} \mathrm{C} 30 \mathrm{~s} ; 60^{\circ} \mathrm{C}$ \\
\hline & NR P8 & 5'-AAACGCAAGTAATACATAAAGTC & for $30 \mathrm{~s}$; and $65^{\circ} \mathrm{C}$ for $1 \mathrm{~min}$; \\
\hline Pfmdr1 SNPs at & OF P9 & 5'-GTGTATTTGCTGTAAGAGCT & 34 cycles of $94^{\circ} \mathrm{C}$ for $30 \mathrm{~s} ; 55^{\circ} \mathrm{C}$ \\
\hline Codon 1034 & OR P10 & 5'-GACATATTAAATAACATGGGTTC & for $1 \mathrm{~min}$ and $72^{\circ} \mathrm{C}$ for 1.5 \\
\hline \multirow[t]{2}{*}{1042 and 1246} & NF P11 & 5' CAGATGATGAAATGTTTAAAGATC & 29 cycles of $94^{\circ} \mathrm{C}$ for $30 \mathrm{~s} ; 60^{\circ} \mathrm{C}$ \\
\hline & NR 12 & 5'-TAAATAACATGGGTTCTTGACT & for $30 \mathrm{~s}$; and $65^{\circ} \mathrm{C}$ for $1 \mathrm{~min}$; \\
\hline pvmdriat codon & OF P13 & 5'-GCGAACTCGAATAAGTACTCCCTCTA & 45 cycles of $94^{\circ} \mathrm{C}$ for $5 \mathrm{~min}$ \\
\hline \multirow[t]{3}{*}{976 and 1076} & OF P14 & 5'GGCGTAGCTTCCCGTAAATAAA & $530 \mathrm{C}$ for $1 \mathrm{~min}$ and $720 \mathrm{C}$ for $1 \mathrm{~min}$ \\
\hline & NF P15 & 5'-GGATTGCTGTCAGCACATATTAACA & 45 cycles of $94^{\circ} \mathrm{C}$ for 5 min, \\
\hline & NF P16 & 5'AGAGGGATTTCATAAAGTCATT & $650 \mathrm{C}$ for $1 \mathrm{~min}$ and $720 \mathrm{C}$ for $1 \mathrm{~min}$ \\
\hline
\end{tabular}


point mutations in pfmdr1, pfcrt and pvmdr1 are illustrated in Table 2.

\section{Detection of pfmdr1 gene copy number variations}

The $p f m d r 1$ gene copy number was estimated by TaqMan real-time PCR, as previously described [29]. Briefly, $10 \mathrm{ng}$ of genomic DNA was amplified in a $25 \mu \mathrm{L}$ volume of reaction mixture containing $1 \mathrm{x}$ TaqMan buffer ( $8 \%$ glycerol, $0.625 \mathrm{U}$ DNA polymerase, $5.5 \mathrm{mmol} / \mathrm{L} \mathrm{MgCl} 2,300 \mu \mathrm{mol} /$ L dNTPs, $600 \mathrm{nmol} / \mathrm{L}$ passive reference dye ROX (5carboxy-X-rhodamine), $\mathrm{pH} 8.3$ ), $300 \mathrm{nmol} / \mathrm{L}$ of each forward and reverse primer, $100 \mathrm{nmol} / \mathrm{L}$ of each probe, and $5 \mu \mathrm{L}$ of template DNA on a Corbett Research RG-3000 (Qiagen, Hilden, Germany). Thermal cycling parameters were as follows: pre-incubation at $95^{\circ} \mathrm{C}$ for 5 minutes, followed by 50 cycles of 15 seconds at $95^{\circ} \mathrm{C}$ and 1 minute at $58^{\circ} \mathrm{C}$. Genomic DNA from $P$. falciparum reference 3D7, reported to have only one copy, was used as the calibrator [39], and $P$. falciparum $ß$-tubulin as the house-keeping gene. For multiple $p f m d r 1$ copy number control, DNA from the $\operatorname{Dd} 2$ clone was used. The $2^{-\Delta \Delta \mathrm{Ct}}$ method of relative quantification [40] was used to estimate copy number. Using this cycle threshold $(\mathrm{Ct})$ method to estimate copy numbers of unknown samples, a calibrator DNA template with known copies of the interest and a house-keeping gene which has the same copy number was utilized. The $\Delta \Delta \mathrm{Ct}$ calculation was as follows: $\Delta \Delta \mathrm{Ct}=(\mathrm{Ct}$ target gene $-\mathrm{Ct} \mathrm{Pf} \beta$-tubulin $)$ $\mathrm{X}$ - (Ct target gene - Ct Pf ß-tubulin) $\mathrm{Y}$, where $\mathrm{X}=$ unknown sample and $\mathrm{Y}=P$. falciparum 3D7. The result was expressed in $\mathrm{N}$-fold changes in $\mathrm{X}$ target gene copies normalized to $P$. falciparum $B$-tubulin according to the equation (amount of target) $=2^{-\Delta \Delta C t}$. Each sample was run as triplicate, and the mean and standard deviation of the three $\mathrm{Ct}$ values were calculated and computed for specificity as suggested earlier [29].

\section{Ethics}

Ethical approvals were obtained from the review boards of Aklilu Lemma Institute of Pathobiology (ALIPB), College of Health Sciences of Jimma University, College of Health and Medical Sciences of Haramaya University and Armauer Hansen Research Institute (AHRI). After obtaining informed consent and assent from either the patient or legal guardian, blood samples were collected from individuals positive for $P$. falciparum or $P$. vivax.
The study participation was voluntary and had no influence on the treatment provision at the respective health facilities. All patient information was kept confidential. All individuals positive for $P$. falciparum were treated with AL, while $P$. vivax positive patients were treated with CQ.

\section{Results}

The observed frequencies of the investigated SNPs in the $p f m d r 1, p f c r t$ and the $p v m d r 1$ loci are summarized in Table 3. The pfcrt K76T (Lys76Thr) mutation was observed in only $15.9 \%(31 / 195)$ of the clinical isolates investigated compared to $84.1 \%(164 / 195)$ wild type allele that were sensitive to CQ. The pfcrt C72S (Cys72Ser) was observed only in $3.6 \%$ (7/195) compared to $96.4 \%$ (188/195) wild type allele that were sensitive to CQ. The pfcrt double mutations (K76T and C72S) were observed in less than $2.6 \%$ of individuals (5/195) Table 3. For the investigated pfmdr1 locus N86Y(Asn86Tyr), the mutation was observed in $14.9 \%(29 / 195)$ of the clinical isolates compared to $85.1 \%(166 / 195)$ wild type that carried sensitive alleles. The investigated pfmdr1 locus Y184 (Tyr184Phe), only $5.1 \%(10 / 195)$ of the clinical isolates carried the mutant. None of the investigated $195 P$. falciparum clinical isolates carried S1034C, N1042D and D1246Y of $p f m d r 1$ polymorphisms. For the investigated pvmdr1 locus Y976 (Tyr976Phe), the mutation was observed in $32.6 \%(70 / 215)$ of the clinical isolates compared to $67.7 \%(145 / 215)$ wild type that carried sensitive alleles, whereas the investigated F1076 (Phe1076Leu) carried no drug resistant mutants Table 3. Of the all investigated $P$. falciparum clinical isolates from Southern and Eastern Ethiopia, only one copy of pfmdr1 gene copy number was observed.

The frequency of SNPs in the pfmdr1, pfcrt and the pvmdr1 loci in Southern and Eastern Ethiopia are summarized in Table 4. The pfcrt K76T mutation in Southern Ethiopia was $13.5 \%(23 / 170)$ of the clinical isolates investigated compared to $86.5 \%(147 / 170)$ wild type allele that were sensitive to CQ. The pfmdr1 locus N86Y was observed in $12.9 \%(22 / 170)$ compared to $87.1 \%(148 / 170)$ wild type allele that were sensitive to CQ. In Eastern Ethiopia, SNPs in the pfmdr1 locus N86Y and pfcrt locus K76T were $28.0 \%(7 / 25)$ and $32.0 \%(8 / 25)$ respectively. On the other hand, for the investigated pvmdr1 locus Y 976 (Tyr976Phe), the mutation was observed in $37.1 \%$ (59/

Table 2 Investigated point mutations in pfmdr1, pfort and pvmdr1genes

\begin{tabular}{|c|c|c|c|c|c|c|c|c|c|c|c|}
\hline \multirow[b]{2}{*}{ Codon position } & \multirow[b]{2}{*}{86} & \multicolumn{4}{|c|}{ Pfmdr1 locus } & \multicolumn{4}{|c|}{ Pfort locus } & \multicolumn{2}{|c|}{ Pvmdr1 locus } \\
\hline & & 184 & 1034 & 1042 & 1246 & 72 & 74 & 75 & 76 & 976 & 1076 \\
\hline Wild type/Mutant & TGA/TGT & ATA/ATT & $\mathrm{CAG} / \mathrm{CTG}$ & TTA/TTG & $\mathrm{GAG} / \mathrm{GAT}$ & $\mathrm{TGT} / \boldsymbol{A} \mathrm{GT}$ & ATG/ATT & $\mathrm{AAT} / \boldsymbol{G A} \boldsymbol{A}$ & $\mathrm{AAA} / \mathrm{ACA}$ & $\mathrm{TAC} / \mathrm{TTC}$ & $\pi T / C T$ \\
\hline ns substitution & Asn/Tyr & Tyr/Phe & Ser/Cys & Asn/Asp & Asp/Tyr & Cys/Ser & Met/lle & Asn/Glu & Lys/Thr & Tyr/Phe & Phe/L \\
\hline
\end{tabular}

ns: non synonymous ; pfmdr1: Plasmodium falciparum multi-drug resistance 1; pfcrt: Plasmodium falciparum chloroquine resistance transporter; pvmdr1: Plasmodium vivax multi-drug resistance 1 . 
Table 3 Distribution of pfcrt, pfmdr1 and pvmdr1 point mutations in the investigated clinical isolates

\begin{tabular}{|c|c|c|c|}
\hline & P. falciparum & number & $\%$ \\
\hline & no resistance alleles detected & 127 & $65 \%$ \\
\hline \multirow[t]{3}{*}{ Pfcrt } & only C72 & 7 & $3.6 \%$ \\
\hline & C72 and K76 & 5 & $2.6 \%$ \\
\hline & only K76 & 31 & $15.9 \%$ \\
\hline pfert and pfmdr1 & K76 and N86 & 4 & $2.1 \%$ \\
\hline \multirow[t]{6}{*}{ pfmdr1 } & only N86 & 29 & $14.9 \%$ \\
\hline & N86 and Y184 & 8 & $4.1 \%$ \\
\hline & only Y184 & 10 & $5.1 \%$ \\
\hline & Total & 195 & \\
\hline & P. vivax & & \\
\hline & no resistance alleles detected & 145 & $74 \%$ \\
\hline \multirow[t]{3}{*}{ pvmdr1 } & only Y976 & 70 & $32.6 \%$ \\
\hline & only F1076 & 0 & $0 \%$ \\
\hline & Total & 145 & \\
\hline
\end{tabular}

159) of the clinical isolates in Southern Ethiopia compared to $19.6 \%(11 / 56)$ in Eastern Ethiopia.

The pfcrt haplotypes were reconstructed for mutations at codons $72-76$ in all $P$. falciparum isolates. The $p f c r t$ wild type Cysteine-Valine-Methionine-Asparagine-Lysine (pfcrt CVMNK) mutates to either Cysteine-ValineIsoleucine-Glutamate-Threonine (pfcrt CVIET) or Serine-Valine-Methionine-Asparagine-Threonine ( $p f c r t$ SVMNT) variants Table 5 . The mutated $p f c r t$ SVMNT haplotype was observed in $4.1 \%(8 / 195)$ of the isolates, whereas pfcrt CVMNK of wildtype was observed in $95.9 \%(187 / 195)$ Table 5. No pfcrt CVIET haplotypes were observed.

Table 4 Distribution of pfcrt, pfmdr1 and pvmdr1 point mutations in the investigated clinical isolates in Southern and Eastern Ethiopia

\begin{tabular}{llcccc}
\hline & P. falciparum & SE no & SE (\%) & EE no & EE (\%) \\
\hline Pfcrt & only C72 & 5 & $2.9 \%$ & 2 & $8.0 \%$ \\
& C72 and K76 & 4 & $2.4 \%$ & 1 & $4.0 \%$ \\
& only K76 & 23 & $13.5 \%$ & 8 & $32.0 \%$ \\
pfcrt and pfmdr1 & K76 and N86 & 2 & $1.2 \%$ & 2 & $8.0 \%$ \\
pfmdr1 & only N86 & 22 & $12.9 \%$ & 7 & $28.0 \%$ \\
& N86 and Y184 & 6 & $3.5 \%$ & 2 & $8.0 \%$ \\
& only Y184 & 7 & $4.1 \%$ & 3 & $12.0 \%$ \\
& P. vivax & & & & \\
pvmdr1 & only Y976 & 59 & $37.1 \%$ & 11 & $19.6 \%$ \\
& only F1076 & 0 & & & $0.0 \%$ \\
\hline
\end{tabular}

pfmdr1: Plasmodium falciparum multi-drug resistance 1; pfcrt: Plasmodium falciparum chloroquine resistance transporter; pvmdr1: Plasmodium. vivax multi-drug resistance 1; SE: Southern Ethiopia; EE: Eastern Ethiopia.

\section{Discussion}

The aim of the current study was to investigate the prevalence of mutant SNPs in the loci pfmdr1, pfcrt, and pvmdr1, as well as copy number variations in $p f m d r 1$, all of which are associated with anti-malarial drug resistance. A large proportion of $P$. falciparum clinical isolates in this study (84.1\%) carried the chloroquine-susceptible pfcrt K76 allele. Previously it has been reported that the CQ-resistant mutation pfcrt $\mathrm{K} 76 \mathrm{~T}$ is a strong predictor of overall CQ resistance, and thus it is used as a biomarker of CQ resistance [16]. It appears that CQsusceptible Plasmodium falciparum isolates are back in circulation in Ethiopia.

The finding of this study does not support a previous study conducted in Ethiopia that reported a 100\% frequency of the pfcrt T76 mutation, and an $81 \%$ frequency of the mutation pfmdr1 Y86 in P. falciparum [41]. However, the current finding is in line with studies conducted in two East African countries [27,42], where the frequency of the pfcrt-76 resistance alleles were repopulated with the sensitive ones after many years of $C Q$ withdrawal. Studies showed that pfcrt mutations at codons 72 to 76 with non-synonymous substitutions result in wildtype pfcrt CVMNK or other pfcrt haplotypes CVIET or SVMNT that have been associated with CQ resistance[43]. The wild type pfcrt CVMNK haplotypes were observed in 187 (95.9\%) of the P. falciparum isolates. The mutant $p f c r t$ SVMNT was carried by $4.1 \%$ (8/ 195) of the investigated isolates, and it was identical to that of chloroquine resistant isolates identified in SouthEast Asia [44]. These are the first findings on the presence of the pfcrt SVMNT haplotype in clinical isolates in Ethiopia. This is an interesting finding and novel to the study as the SVMNT haplotype is still very rare in Africa. So far few studies reported the presence of this haplotype in African countries [45-48], of this haplotype mostly associated with amodiaquine resistance and lower level of chloroquine resistance compared to CVIET $[49,50]$. The pfcrt CVIET haplotypes were not detected here, although it is prevalent in Africa [51].

Concerning $p f m d r 1$, while wild-type $p f m d r 1$ is thought to transport and accumulate CQ in the parasites' food vacuole, mutations N86Y, S1034C, N1042D, and D1246Y interfere with transportation of the anti-malarial drugs, leading to reduced CQ-sensitivity [14]. The percentage of wild-type alleles at codon 86 of pfmdr1 was $85.1 \%$ (166/ 195), which is higher than $81 \%$ present in Schunk in 2006 and $84.5 \%$ in Eshetu in 2010 [41,52]. It should be clear that the study by Schunk in 2006 was conducted 7 years before the current study. This is clear that as the time difference between these two studies is large and with reduced drug pressure on CQ over time might have contributed to the return of $C Q$ susceptibility. 
Table 5 Distribution of reconstructed Pfcrt haplotypes from clinical isolates from South and Eastern Ethiopia

\begin{tabular}{|c|c|c|c|}
\hline Locus & haplotype & Investigated fragment $\left(5^{\prime}-3^{\prime}\right)$ & Number (\%) \\
\hline \multirow[t]{3}{*}{ pfcrt 74-76 } & CVMNK (Sensitive) & 5'-TAATTGAAACAATTाTTG-3' & $187(95.9)$ \\
\hline & SVMNT (Mutant) & 5'-TAATGAATAAAATTाTG-3' & $8(4.1)$ \\
\hline & CVIET (Mutant) & 5'-TAATGAATACAATTTTG-3' & 0 \\
\hline
\end{tabular}

pfmdr1: Plasmodium falciparum multi-drug resistance 1; pfcrt: Plasmodium falciparum chloroquine resistance transporter; pvmdr1: Plasmodium vivax multi-drug resistance 1.

The pfcrt K76T mutation in Southern Ethiopia was $13.5 \%(23 / 170)$ of the clinical isolates investigated compared to $86.5 \%(147 / 170)$ wild type allele that were sensitive to CQ. The pfmdr1 locus N86Y was observed in $12.9 \%(22 / 170)$ compared to $87.1 \%$ (148/170) wild type allele that were sensitive to CQ. In Eastern Ethiopia, SNPs in the pfmdr1 locus N86Y and pfcrt locus K76T were $28.0 \%(7 / 25)$ and $32 \%(8 / 25)$ respectively. There was no statistical difference between Southern and Eastern Ethiopia in SNPs in the pfmdr1 locus N86Y and pfcrt locus K76T ( $\mathrm{P}=0.9)$.

Double mutations in $p v m d r 1$ at positions $\mathrm{Y} 976 \mathrm{~F}$ and F1076L have been suggested to be associated with reduced chloroquine susceptibility to $P$. vivax in Thailand and Indonesia, the two countries where $P$. vivax is prevalent. Other studies have addressed whether chloroquine or amodiaquine treatment failure might be associated with $P$. vivax isolates carrying the Y976F substitution [53]. Pvmdr1 sequences from P.vivax, the orthologue of pfmdr1, were analyzed for the presence of mutations at positions 976 and 1076, and we found that 32.6\% (70/215) of the isolates carried the F976 SNP. Mutations were not detected at codon 1076 in all P. vivax isolates studied here. On the other hand, for the investigated pvmdr1 locus Y976 (Tyr976Phe), the mutation was observed in $37.1 \%(59 / 159)$ of the clinical isolates from Southern Ethiopia compared to $19.6 \%$ (11/56) from Eastern Ethiopia.

In line with the current study, studies conducted in Madagascar and Brazil showed that F1076L cannot be taken as an indicator of drug resistance, but rather it is a geographic variant $[46,53,54]$. Earlier, in vivo studies conducted in Ethiopia confirmed the presence of drug resistant $P$. vivax $[8,35]$. However, these studies were confounded by the inherent difficulties associated with in vivo tests for relapsing malaria [55] and the difficulties in differentiating between re-infection, recrudescence, and relapse after treatment failure [56].

A high proportion $(97.9 \%, 191 / 195)$ of samples had chloroquine (CQ)-susceptible alleles at both codon 76 of pfcrt and codon 86 of pfmdr1. The rapid shift in $P$. falciparum from CQ-resistant to CQ-susceptible suggests that the removal of CQ for the treatment of $P$. falciparum or the pressure from $\mathrm{AL}$ that has been used since 2004 to treat falciparum malaria and mixed infection of P.falciparum and P. vivax or both may eventually lead to replacement of $p f m d r 1$ resistance genes by susceptible parasite populations $[42,57]$. Our finding was consistent with observations from Malawi [57], Kenya [42], and Tanzania [27], where the withdrawal of chloroquine resulted in the rapid spread of a chloroquinesusceptible Pfcrt K76 population. In Malawi, recovery of the susceptible Pfcrt-K76 from $<15 \%$ to $100 \%$ within 13 years of CQ withdrawal has been reported [57]. Moreover, a study confirmed that the pfmdr 1 alleles $86 \mathrm{~N}, 184 \mathrm{~F}$, and 1246D significantly increased in prevalence after AL treatment [58]. In another in vivo study, P. falciparum parasites carrying the chloroquine-susceptible pfcrt $\mathrm{K} 76$ allele was selected after treatment with AL [59].

It was difficult to determine whether the CQsusceptible resurgence is due to back-mutations in the CQ-resistant allele or the expansion of surviving CQsusceptible reservoir populations. Re-expansion appears to be more common in Africa, where transmission rates are higher and naturally immune individuals are more common than in Southeast Asia (where CQ-resistant alleles appear to have gone to fixation in many areas) [57]. It does not appear that CQ-resistant mutants in Ethiopia acquired mutations to compensate for the costs of being drug-resistant. It is believed that such compensatory mutations confer fitness levels greater than that of the original CQ-susceptible and CQ-resistant alleles [60]. CQ-susceptible alleles clearly have a selective advantage over resistant ones, $p f m d r 1$ Y 86 having rebounded from $100 \%$ to $11 \%$ in 6 years (for samples collected on 2009 from East Ethiopia) to eight years time (for samples collected on 2011from South Ethiopia). On the other hand, N86Y mutation was rebounded from $81 \%$ to $9 \%$ [41,52].

In Ethiopia, due to resistance developed by P. falciparum, replacement of SP by artemether-lumefantrine has been mandatory. Since 2004, artemether-lumefantrine has been the drug of choice for the treatment of $P$. falciparum malaria. Unlike Malawi, in Ethiopia CQ was partially withdrawn and is still the drug of choice for the treatment of uncomplicated $P$. vivax. This finding shows that there has been strong selection for chloroquine-sensitive parasites after the nationwide replacement of chloroquine with SP. The return of chloroquine-susceptible alleles in a country like Ethiopia, which is endemic for malaria, can be considered a positive development toward replacing the expensive artemether-lumefantrine with a safe and cheap form of CQ in combination with other short-acting drugs. Likewise, in 
malaria-endemic countries even partial returns of chloroquine sensitivity have a positive impact on public health [57].

\section{Conclusion}

The return of CQ-sensitive parasites is likely due to either CQ withdrawal for the treatment of $P$. falciparum or the pressure from AL since 2004 or both. The return of CQ-susceptible P. falciparum following declining CQ resistance will have its own contribution in the battle against malaria. If chloroquine susceptibility does become widespread in Ethiopia,the possibility of using chloroquine in the future as a combination therapy with other short-acting drugs with different pharmacokinetic and pharmacodynamics profiles will be an additional anti-malarial option. This is a positive development, since CQ is cheap, safe, well-tolerated, long-lasting, and easy-to-prepare molecule. Additional surveillance studies to investigate resistance markers of $p f m d r 1$ and Pfcrt genes of $P$. falciparum in the same geographic area may help to assess the prevalence of antimalarial resistance.

\section{Competing interests}

The authors have declared that they have no competing interests.

\section{Authors' contributions}

SKM designed and performed the field study and experiments, data analysis with drafting first draft. $A A, N B, T G, R C, \Pi$ and $G M$ contributed to the study design and study samples and revisions of MS. TPV designed the experiments, contributed to materials and tools, supervised the experiments, revision of the MS. All authors read and approved the final manuscript.

\section{Acknowledgements}

We thank all our study volunteers. We are grateful to all the health personnel at the field sites for their extensive help in this study. We would like to thank all patients and their relatives for their participation. We are grateful to all the health personnel at the field sites for their extensive help. A special thanks to Abebaw Tiruneh, Albert Lalremruata and Justin Anthony for sharing their expertise.

\section{Funding}

SKM was supported by a DAAD fellowship to do laboratory work in University of Tübingen. The laboratory work was supported by internal grant to author TPV. Moreover, the field work for this research was supported by funds from the Sida and NORAD core grant to the Armauer Hansen Research Institute and University thematic research program of Addis Ababa University.

\footnotetext{
Author details

${ }^{1}$ Aklilu Lemma Institute of Pathobiology, Addis Ababa University, Addis Ababa, Ethiopia. ${ }^{2}$ Armauer Hansen Research Institute, Addis Ababa, Ethiopia. ${ }^{3}$ Institute of Tropical Medicine, University of Tübingen, Tübingen, Germany. ${ }^{4}$ Department of Medical Laboratory Science, College of Medical Sciences, Haramaya, Ethiopia. ${ }^{5}$ Department of Bioinformatics and Genomics at University of North Carolina, Charlotte, North Carolina, USA. ${ }^{6}$ Fondation Congolaise pour la Recherche Medicale, Brazzaville, Republic of Congo. ${ }^{7}$ Addis Ababa University and Armauer Hansen Research Institute, Addis Ababa, Ethiopia.
}

Received: 2 April 2014 Accepted: 19 June 2014

Published: 25 June 2014

\section{References}

1. Kebede S, Aseffa A, Medhin G, Berhe N, Velavan TP: Re-evaluation of microscopy confirmed Plasmodium falciparum and Plasmodium vivax malaria by nested PCR detection in southern Ethiopia. Malar J 2014, $13: 48$

2. Nevill CG: Malaria in sub-Saharan Africa. Soc Sci Med 1990, 31:667-669.

3. O'Meara WP, Mangeni JN, Steketee R, Greenwood B: Changes in the burden of malaria in sub-Saharan Africa. Lancet Infect Dis 2010, 10:545-555.

4. WHO: World Malaria Report. Geneva, Switzerland: World Health Organization fact sheet; 2013

5. Olatunde A: Chloroquine-resistant Plasmodium falciparum and malaria in Africa. Trans R Soc Trop Med Hyg 1977, 71:80-81.

6. Campbell CC, Chin W, Collins WE, Teutsch SM, Moss DM: Chloroquineresistant Plasmodium falciparum from East Africa: cultivation and drug sensitivity of the Tanzanian I/CDC strain from an American tourist. Lancet 1979, 2:1151-1154.

7. Dondorp AM, Nosten F, Yi P, Das D, Phyo AP, Tarning J, Lwin KM, Ariey F, Hanpithakpong W, Lee SJ, Ringwald P, Silamut K, Imwong M, Chotivanich K, Lim P, Herdman T, An SS, Yeung S, Singhasivanon P, Day NP, Lindegardh N, Socheat $D$, White $\mathrm{NJ}$ : Artemisinin resistance in Plasmodium falciparum malaria. N Engl J Med 2009, 361:455-467.

8. Tulu AN, Webber RH, Schellenberg JA, Bradley DJ: Failure of chloroquine treatment for malaria in the highlands of Ethiopia. Trans $R$ Soc Trop Med Hyg 1996, 90:556-557.

9. Abebe W: Therapeutic efficacy of sulfadoxin/pyrimethamine in the treatment of uncomplicated Plasmodium falciparum malaria in Enseno, Meskan Woreda, Gurage zone, SNNPR, Ethiopia. Ethiop Med J 2006, 44:133-138.

10. Gebru-Woldearegai T, Hailu A, Grobusch MP, Kun JF: Molecular surveillance of mutations in dihydrofolate reductase and dihydropteroate synthase genes of Plasmodium falciparum in Ethiopia. Am J Trop Med Hyg 2005, 73:1131-1134

11. Degefa T: In vivo sulphadoxine-pyrimethamine sentitivity study Tigray Region, Southern Zone, Alamata Town, September-November 2001. Ethiop Med J 2004, 42:35-39.

12. Jima D, Tesfaye G, Medhin A, Kebede A, Argaw D, Babaniyi O: Efficacy of sulfadoxine-pyrimethamine for the treatment of uncomplicated falciparum malaria in Ethiopia. East Afr Med J 2005, 82:391-395.

13. FMOH: Malaria Diagnosis and Treatment a Guideline for Health Workers in Ethiopia, Ethiopian Federal Ministry of Health Guideline. ; 2004.

14. Andriantsoanirina $V$, Ratsimbasoa A, Bouchier C, Tichit M, Jahevitra M, Rabearimanana S, Raherinjafy R, Mercereau-Puijalon O, Durand R, Menard D: Chloroquine clinical failures in $P$. falciparum malaria are associated with mutant Pfmdr-1, not Pfcrt in Madagascar. PLoS One 2010, 5:e13281.

15. Dlamini SV, Beshir K, Sutherland CJ: Markers of anti-malarial drug resistance in Plasmodium falciparum isolates from Swaziland: identification of pfmdr1$86 \mathrm{~F}$ in natural parasite isolates. Malar J 2010, 9:68.

16. Griffing S, Syphard L, Sridaran S, McCollum AM, Mixson-Hayden T, Vinayak S, Villegas L, Barnwell JW, Escalante AA, Udhayakumar V: pfmdr1 amplification and fixation of pfort chloroquine resistance alleles in Plasmodium falciparum in Venezuela. Antimicrob Agents Chemother 2010, 54:1572-1579.

17. Wurtz N, Fall B, Pascual A, Diawara S, Sow K, Baret E, Diatta B, Fall KB, Mbaye PS, Fall F, Dieme Y, Rogier C, Bercion R, Briolant S, Wade B, Pradines B: Prevalence of molecular markers of Plasmodium falciparum drug resistance in Dakar, Senegal. Malar J 2012, 11:197.

18. Baro NK, Callaghan PS, Roepe PD: Function of resistance conferring Plasmodium falciparum chloroquine resistance transporter isoforms. Biochemistry 2013, 52:4242-4249.

19. Fidock DA, Nomura T, Talley AK, Cooper RA, Dzekunov SM, Ferdig MT, Ursos LM, Sidhu AB, Naude B, Deitsch KW, Su XZ, Wootton JC, Roepe PD, Wellems TE: Mutations in the $P$. falciparum digestive vacuole transmembrane protein PfCRT and evidence for their role in chloroquine resistance. Mol Cell 2000, 6:861-871

20. Norahmad NA, Abdullah NR, Yaccob N, Jelip J, Dony JF, Ruslan KF, Sulaiman LH, Sidek HM, Noedl H, Ismail Z: High prevalence of pfcrt K76t mutants among Plasmodium falciparum isolates from Sabah, Malaysia. Southeast Asian J Trop Med Public Health 2011, 42:1322-1326.

21. Sanchez $C P$, McLean JE, Rohrbach P, Fidock DA, Stein WD, Lanzer M: Evidence for a pfcrt-associated chloroquine efflux system in the human malarial parasite Plasmodium falciparum. Biochemistry 2005, 44:9862-9870. 
22. Brega S, Meslin B, De Monbrison F, Severini C, Gradoni L, Udomsangpetch R, Sutanto I, Peyron F, Picot S: Identification of the Plasmodium vivax mdr-like gene (pvmdr1) and analysis of single-nucleotide polymorphisms among isolates from different areas of endemicity. J Infect Dis 2005 , 191:272-277.

23. Mula P, Fernandez-Martinez A, de Lucio A, Ramos JM, Reyes F, Gonzalez V Benito A, Berzosa P: Detection of high levels of mutations involved in anti-malarial drug resistance in Plasmodium falciparum and Plasmodium vivax at a rural hospital in southern Ethiopia. Malar J 2011, 10:214.

24. Duraisingh MT, Cowman AF: Contribution of the pfmdr1 gene to antimalarial drug-resistance. Acta Trop 2005, 94:181-190.

25. Valderramos SG, Fidock DA: Transporters involved in resistance to antimalarial drugs. Trends Pharmacol Sci 2006, 27:594-601.

26. Picot $S$, Olliaro P, De Monbrison F, Bienvenu AL, Price RN, Ringwald P. A systematic review and meta-analysis of evidence for correlation between molecular markers of parasite resistance and treatment outcome in falciparum malaria. Malar J 2009, 8:89.

27. Mohammed A, Ndaro A, Kalinga A, Manjurano A, Mosha JF, Mosha DF, Van Zwetselaar M, Koenderink JB, Mosha FW, Alifrangis M, Reyburn H, Roper C, Kavishe RA: Trends in chloroquine resistance marker, Pfcrt-K76T mutation ten years after chloroquine withdrawal in Tanzania. Malar J 2013, 12:415.

28. Vathsala PG, Pramanik A, Dhanasekaran S, Devi CU, Pillai CR, Subbarao SK, Ghosh SK, Tiwari SN, Sathyanarayan TS, Deshpande PR, Mishra GC, Ranjit MR, Dash AP, Rangarajan PN, Padmanaban G: Widespread occurrence of the Plasmodium falciparum chloroquine resistance transporter (Pfcrt) gene haplotype SVMNT in P. falciparum malaria in India. Am J Trop Med Hyg 2004, 70:256-259.

29. Price RN, Uhlemann AC, Brockman A, McGready R, Ashley E, Phaipun L, Patel R, Laing K, Looareesuwan S, White NJ, Nosten F, Krishna S: Mefloquine resistance in Plasmodium falciparum and increased pfmdr1 gene copy number. Lancet 2004, 364:438-447.

30. Ballut PC, Siqueira AM, Orlando AC, Alexandre MA, Alecrim MG, Lacerda MV: Prevalence and risk factors associated to pruritus in Plasmodium vivax patients using chloroquine in the Brazilian Amazon. Acta Trop 2013, 128:504-508.

31. Galappaththy GN, Tharyan P, Kirubakaran R: Primaquine for preventing relapse in people with Plasmodium vivax malaria treated with chloroquine. Cochrane Database Syst Rev 2013, 10, CD004389.

32. Ganguly S, Saha P, Guha SK, Das S, Bera DK, Biswas A, Kundu PK, Saha B, Ray K, Maji AK: In vivo therapeutic efficacy of chloroquine alone or in combination with primaquine against vivax malaria in Kolkata, West Bengal, India, and polymorphism in pvmdr1 and pvcrt-o genes. Antimicrob Agents Chemother 2013, 57:1246-1251.

33. Rieckmann $\mathrm{KH}$, Davis DR, Hutton DC: Plasmodium vivax resistance to chloroquine? Lancet 1989, 2:1183-1184

34. Baird JK, Sustriayu Nalim MF, Basri H, Masbar S, Leksana B, Tjitra E, Dewi RM, Khairani M, Wignall FS: Survey of resistance to chloroquine by Plasmodium vivax in Indonesia. Trans R Soc Trop Med Hyg 1996, 90:409-411.

35. Teka H, Petros B, Yamuah L, Tesfaye G, Elhassan I, Muchohi S, Kokwaro G, Aseffa $\mathrm{A}$, Engers $\mathrm{H}$ : Chloroquine-resistant Plasmodium vivax malaria in Debre Zeit, Ethiopia. Malar J 2008, 7:220.

36. Vestergaard LS, Ringwald P: Responding to the challenge of antimalarial drug resistance by routine monitoring to update national malaria treatment policies. Am J Trop Med Hyg 2007, 77:153-159.

37. Snounou G, Beck HP: The use of PCR genotyping in the assessment of recrudescence or reinfection after antimalarial drug treatment. Parasitol Today 1998, 14:462-467.

38. Humphreys GS, Merinopoulos I, Ahmed J, Whitty CJ, Mutabingwa TK, Sutherland CJ, Hallett RL: Amodiaquine and artemether-lumefantrine select distinct alleles of the Plasmodium falciparum mdr1 gene in Tanzanian children treated for uncomplicated malaria. Antimicrob Agents Chemother 2007, 51:991-997.

39. Ferreira ID, Rosario VE, Cravo PV: Real-time quantitative PCR with SYBR Green I detection for estimating copy numbers of nine drug resistance candidate genes in Plasmodium falciparum. Malar J 2006, 5:1.

40. Livak KJ, Schmittgen TD: Analysis of relative gene expression data using real-time quantitative PCR and the 2(-Delta Delta $C(T))$ Method. Methods 2001, 25:402-408.

41. Schunk M, Kumma WP, Miranda IB, Osman ME, Roewer S, Alano A, Loscher T, Bienzle U, Mockenhaupt FP: High prevalence of drug-resistance mutations in Plasmodium falciparum and Plasmodium vivax in southern Ethiopia. Malar J 2006, 5:54.
42. Mang'era CM, Mbai FN, Omedo IA, Mireji PO, Omar SA: Changes in genotypes of Plasmodium falciparum human malaria parasite following withdrawal of chloroquine in Tiwi, Kenya. Acta Trop 2012, 123:202-207.

43. Dittrich S, Alifrangis M, Stohrer JM, Thongpaseuth V, Vanisaveth $\mathrm{V}$, Phetsouvanh R, Phompida S, Khalil IF, Jelinek T: Falciparum malaria in the north of Laos: the occurrence and implications of the Plasmodium falciparum chloroquine resistance transporter (pfcrt) gene haplotype SVMNT. Trop Med Int Health 2005, 10:1267-1270.

44. Awasthi G, Prasad GB, Das A: Population genetic analyses of Plasmodium falciparum chloroquine receptor transporter gene haplotypes reveal the evolutionary history of chloroquine-resistant malaria in India. Int J Parasitol 2011, 41:705-709.

45. Alifrangis M, Dalgaard MB, Lusingu JP, Vestergaard LS, Staalsoe T, Jensen AT, Enevold A, Ronn AM, Khalil IF, Warhurst DC, Lemnge MM, Theander TG, Bygbjerg IC: Occurrence of the Southeast Asian/South American SVMNT haplotype of the chloroquine-resistance transporter gene in Plasmodium falciparum in Tanzania. J Infect Dis 2006, 193:1738-1741.

46. Gama BE, Oliveira NK, Souza JM, Daniel-Ribeiro CT, Ferreira-da-Cruz MF: Characterisation of pvmdr1 and pvdhfr genes associated with chemoresistance in Brazilian Plasmodium vivax isolates. Mem Inst Oswaldo Cruz 2009, 104:1009-1011.

47. Gbotosho GO, Folarin OA, Bustamante C, Da Silva LH, Mesquita E, Sowunmi A, Zalis MG, Oduola AM, Happi CT: Different patterns of pfort and pfmdr1 polymorphisms in P. falciparum isolates from Nigeria and Brazil: the potential role of antimalarial drug selection pressure. Am J Trop Med Hyg 2012, 86:211-213.

48. Mehlotra RK, Mattera G, Bockarie MJ, Maguire JD, Baird JK, Sharma YD, Alifrangis M, Dorsey G, Rosenthal PJ, Fryauff DJ, Kazura JW, Stoneking M, Zimmerman PA: Discordant patterns of genetic variation at two chloroquine resistance loci in worldwide populations of the malaria parasite Plasmodium falciparum. Antimicrob Agents Chemother 2008, 52:2212-2222.

49. Sa JM, Twu O, Hayton K, Reyes S, Fay MP, Ringwald P, Wellems TE: Geographic patterns of Plasmodium falciparum drug resistance distinguished by differential responses to amodiaquine and chloroquine. Proc Natl Acad Sci U S A 2009, 106:18883-18889.

50. Sa JM, Twu O: Protecting the malaria drug arsenal: halting the rise and spread of amodiaquine resistance by monitoring the PfCRT SVMNT type. Malar J 2010, 9:374.

51. Menard S, Morlais I, Tahar R, Sayang C, Mayengue PI, Iriart X, Benoit-Vical F, Lemen B, Magnaval JF, Awono-Ambene P, Basco LK, Berry A: Molecular monitoring of Plasmodium falciparum drug susceptibility at the time of the introduction of artemisinin-based combination therapy in Yaounde, Cameroon: implications for the future. Malar J 2012, 11:113.

52. Eshetu T, Berens-Riha N, Fekadu S, Tadesse Z, Gurkov R, Holscher M, Loscher T, Miranda IB: Different mutation patterns of Plasmodium falciparum among patients in Jimma University Hospital, Ethiopia. Malar J 2010, 9:226.

53. Marfurt J, De Monbrison F, Brega S, Barbollat L, Muller I, Sie A, Goroti M, Reeder JC, Beck HP, Picot S, Genton B: Molecular markers of in vivo Plasmodium vivax resistance to amodiaquine plus sulfadoxinepyrimethamine: mutations in pvdhfr and pvmdr1. J Infect Dis 2008, 198:409-417.

54. Barnadas C, Ratsimbasoa A, Tichit M, Bouchier C, Jahevitra M, Picot S, Menard D: Plasmodium vivax resistance to chloroquine in Madagascar: clinical efficacy and polymorphisms in pvmdr1 and pvcrt-o genes. Antimicrob Agents Chemother 2008, 52:4233-4240.

55. Baird JK, Leksana B, Masbar S, Fryauff DJ, Sutanihardja MA, Suradi, Wignall FS, Hoffman SL: Diagnosis of resistance to chloroquine by Plasmodium vivax: timing of recurrence and whole blood chloroquine levels. Am J Trop Med Hyg 1997, 56:621-626.

56. Chen N, Auliff A, Rieckmann K, Gatton M, Cheng Q: Relapses of Plasmodium vivax infection result from clonal hypnozoites activated at predetermined intervals. J Infect Dis 2007, 195:934-941.

57. Laufer MK, Takala-Harrison S, Dzinjalamala FK, Stine OC, Taylor TE, Plowe CV: Return of chloroquine-susceptible falciparum malaria in Malawi was a reexpansion of diverse susceptible parasites. J Infect Dis 2010, 202:801-808.

58. Dokomajilar C, Nsobya SL, Greenhouse B, Rosenthal PJ, Dorsey G: Selection of Plasmodium falciparum pfmdr1 alleles following therapy with artemether-lumefantrine in an area of Uganda where malaria is highly endemic. Antimicrob Agents Chemother 2006, 50:1893-1895. 
59. Sisowath C, Petersen I, Veiga MI, Martensson A, Premji Z, Bjorkman A, Fidock DA, Gil JP: In vivo selection of Plasmodium falciparum parasites carrying the chloroquine-susceptible pfcrt K76 allele after treatment with artemether-lumefantrine in Africa. J Infect Dis 2009, 199:750-757.

60. Levin BR, Perrot V, Walker N: Compensatory mutations, antibiotic resistance and the population genetics of adaptive evolution in bacteria. Genetics 2000, 154:985-997.

doi:10.1186/1475-2875-13-244

Cite this article as: Mekonnen et al:: Return of chloroquine-sensitive Plasmodium falciparum parasites and emergence of chloroquineresistant Plasmodium vivax in Ethiopia. Malaria Journal 2014 13:244.

\section{Submit your next manuscript to BioMed Central and take full advantage of:}

- Convenient online submission

- Thorough peer review

- No space constraints or color figure charges

- Immediate publication on acceptance

- Inclusion in PubMed, CAS, Scopus and Google Scholar

- Research which is freely available for redistribution 